\title{
Four new species of Megaselia Rondani (Diptera: Phoridae) from France
}

\author{
R. Henry L. DISNEY* and René SIFFOINTE** \\ *Department of Zoology, University of Cambridge, Cambridge CB2 3EJ, England; e-mail: rhld2@hermes.cam.ac.uk, \\ **1670 rue du Crêt, 74700, Sallanches, France; e-mail: rene.siffointe@wanadoo.fr,
}

\begin{abstract}
Among Phoridae collected at Sallanches (France, Rhône-Alpes) are Megaselia marekdurskii Disney, previously only known from Poland, and the new species: $M$. betrugspinata Disney sp. n., $M$. museoconfluentis Disney sp. n., M. siffointei Disney sp. n. and $M$. similipropinqua Disney sp. n.
\end{abstract}

Key words: Phoridae, France, new species

\section{INTRODUCTION}

The material of Phoridae were collected on the Le Crêt de Saint-Martin in the town of Sallanches (74700), in France by the second author (RS) near his home. Some problem specimens preserved in $70 \%$ ethanol, were sent to RHLD, who prepared slide mounts in Berlese Fluid (Disney 2001). The results are reported below.

\section{Megaselia betrugspinata Disney n. sp.}

(Figs 1-5)

Diagnosis (male). In the key to the males of the British species (Disney 1989) this species runs to couplets 48 and 59. It and M. spinata differ from the other species of these couplets in lacking a left hypandrial lobe but possessing a right lobe. In the case of $M$. spinata this lobe is larger and is covered with microtrichia (Figs $6 \& 7$ ). In the new species it is smaller and largely bare. In addition it lacks the sclerite (vestige of tergite 10) at the base of the anal tube. This feature is labelled in Textfig. 272 in Schmitz's (1958) illustration of the hypopygium of $M$. gemina Schmitz, which is a synonym of M. spinata (Disney 1988). In the keys of Schmitz (1957) M betrugspinata runs to couplet 22 of Abteilung II. Some specimens of M. spinata will run to the same couplet. The rest are keyed out in Abteilung III (Schmitz 1958). The omission of $M$. spinata from Abteilung II was caused by not allowing for the variation in the costal index across the divide between the $\mathrm{CI}$ being long or short.

Male. Head as in Fig. 3, with the frons brown, clearly broader than long, with 50-56 hairs and dense but very fine microtrichia. Supra-antennal bristles (SAs) with the lower pair robust but $0.8-09.9$ times as long as upper SAs. The antials slightly lower on frons than anterolaterals (Als), and about a third to half as far from an AL bristle as either is from an upper SA bristle. Pre-ocellars 0.5-1.0 times further apart than either is from a mediolateral bristle, which is slightly higher on frons. Cheek with 3-4 bristles and jowl with two that are longer and more robust. The subglobose postpedicels brown, without subcutaneous pit sensilla (SPS) vesicles, and as in Fig. 1. Palp yellowish grey, at most about a third as broad as postpedicel but slightly longer than breadth of latter, with 5-6 bristles (the longest being about 0.6 times as long as palp) and 6-8 hairs. Labrum light brown and about a third as wide as a postpedicel Labella pale and with very few short spinules below. Thorax brown. Three notopleural bristles and no cleft in front of these. Mesopleuron with 8-11 hairs and a bristle (about equal to middle 
notopleural). Scutellum with an anterior pair of hairs (about equal to those in middle of scutum) and a posterior pair of bristles. Apart from brown patch on mid coxa, legs light brown to yellowish brown, the front leg being palest. Fore tarsus with posterodorsal hair palisade on segments 1-5 and 5 a little shorter than 4 . Dorsal hair palisade of mid tibia extends about 0.7 times its length. Hairs below basal half of hind femur longer than those of anteroventral row of outer half (Fig. 4). Hind tibia with at least a dozen differentiated posterodorsal hairs and spinules of apical combs simple. Wing (Fig. 5) 1.9-2.1 mm long. Costal index 0.49-0.51. Costal ratios 3.0-3.7: 1.3-1.8: 1. Costal cilia (of section 3) $0.08-0.10 \mathrm{~mm}$ long. No hair at base of vein 3 . With 2 axillary bristles, the outer being $0.11-0.13 \mathrm{~mm}$ long, and thus just longer than costal cilia. Sc not reaching R1. Thick veins brown but not dark, thin veins 4-6 brown, 7 pale grey. Membrane tinged grey (evident to naked eye when viewed against a white background). Haltere brown. Abdominal tergites brown with hairs that are longest at rear margins especially on T6 (Fig. 2) and towards the sides of T2. Venter grey, and with hairs on segments 5 and 6 about $0.07 \mathrm{~mm}$ long, but those on 3-4 being much finer and only $0.04 \mathrm{~mm}$ long or less (and easily overlooked at low magnifications). Hypopygium mainly brown, with a brownish grey anal tube and paler right hypandrial lobe, and as Figs $1 \& 2$.

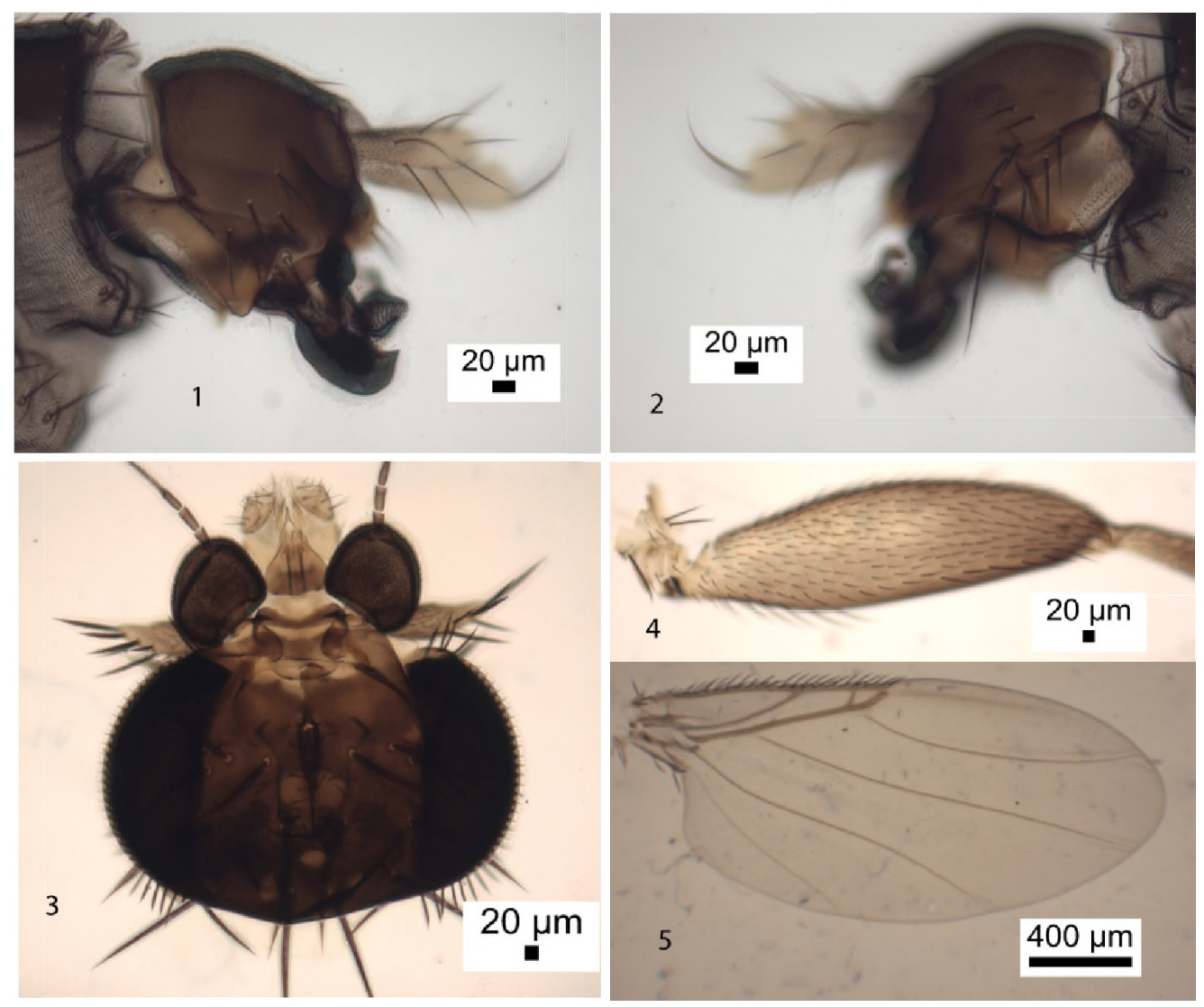

Figs 1-5. Megaselia betrugspinata $n$. sp., male: 1 - left face of hypopygium; 2 - right face of hypoygium; 3 -frontal view of head; 4 - hind femur; 5 - wing. 
Material examined. Holotype male, France, Sallanches, Le Crêt de Saint-Martin, Oct 2012, R. Siffointe (M110, University of Cambridge, Museum of Zoology, 8-173). 2 paratype males as holotype

Etymology. Named after its close resemblance to $M$. spinata (Wood); Betrug meaning a deception.
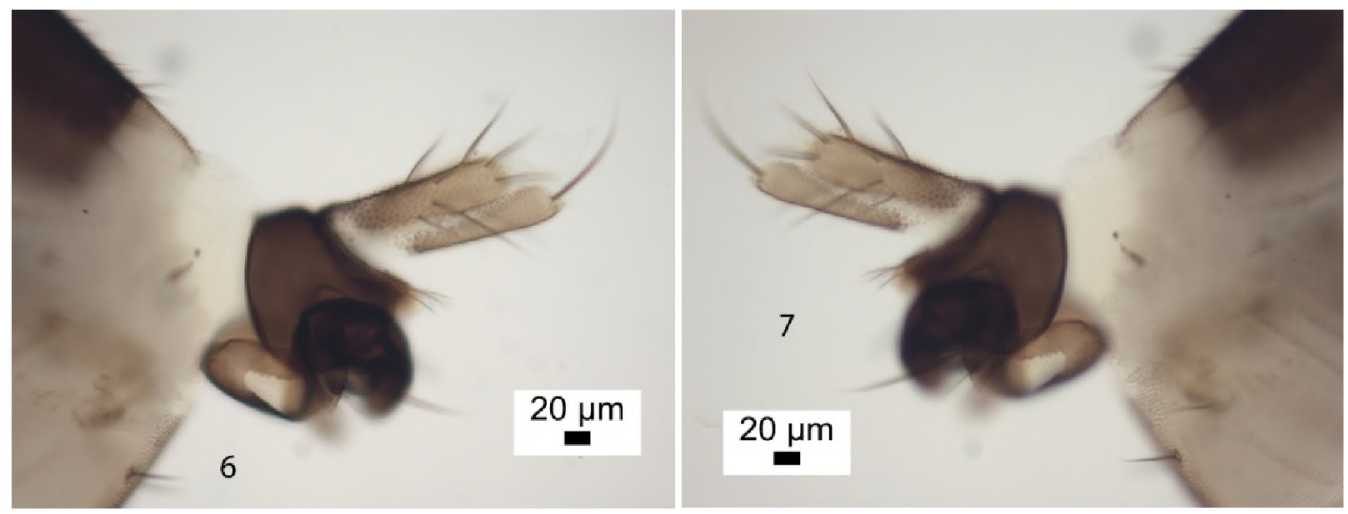

Figs 6-7. Megaselia spinata (Wood) male hypopygium: 6 - left face; 7 - right face.

\section{Megaselia marekdurskii Disney, 1998}

Megaselia marekdurskii Disney, in Disney \& Durska 1998: 442 (male)

The type material of this species from Poland is paler than the following specimens collected in France. However, it had been in alcohol for more than 10 years before being slide mounted. It is thought that it had faded somewhat during this time. In our material the postpedicels, palps, abdominal tergites and legs are darker than in the type material. 2012.

Material examined. 2 males, France, Sallanches, Le Crêt de Saint-Martin, Jul and Aug

\section{Megaselia museoconfluentis Disney n. sp.}

(Figs 8-14)

Diagnosis (male). In the key to the males of the British species (Disney 1989) this species runs to couplets 79 and 80 , but is immediately distinguished by its hypopygium, which also distinguishes it from subsequently described species running to these couplets. Indeed the highly distinctive enlarged right paraphysis of the penis complex will alone immediately distinguish it. Specimens with the costal index of 0.44 or more will fail to run down in the key of Schmitz \& Beyer (1965), but perhaps coming closest to M. pachydactyla Schmitz but is twice the size of this species. Specimens with the costal index less than 0.44 will run to couplet 6 in the key Schmitz \& Delage (1974), to M. divergens (Malloch), which however is a Nearctic species confused with the European species $M$ fenestralis (Schmitz) which had been incorrectly synonymised with Malloch's species (Disney 1987). The hypopygium will immediately distinguish our new species from $M$ fenestralis.

Male. Head as Fig. 8. Frons brown, clearly broader than long, with 40-56 hairs and dense but very fine microtrichia. Supra-antennal bristles (SAs) subequal, the lower pair being about 0.94-0.98 times as long as the upper SAs. The antials a little lower on frons than anterolaterals (ALs), and about 1.4 times as far from upper SAs as either is from an AL bristle. Pre-ocellars a 
little closer together than either is from a mediolateral bristle, which is at about the same level on frons. Cheek with 3-6 bristles and jowl with 3 longer bristles. The subglobose postpedicel brown, without subcutaneous pit sensilla (SPS) vesicles, and as Fig. 8. Palp yellowish grey, at most a quarter as broad as a postpedicel but about 1.5 times as long as breadth of latter, with 5-8 bristles (the longest being almost two thirds as long as the palp) and 5-9 hairs. Labrum light brown and about three quarters the width of a postpedicel. Labella pale but each with a narrow brown band above and with very few short spinules below. Thorax brown. Three notopleural bristles and no cleft in front of these. Mesopleuron with 8-24 hairs. Scutellum with an anterior pair of hairs (at most as long as those in middle of scutum) and a posterior pair of bristles.

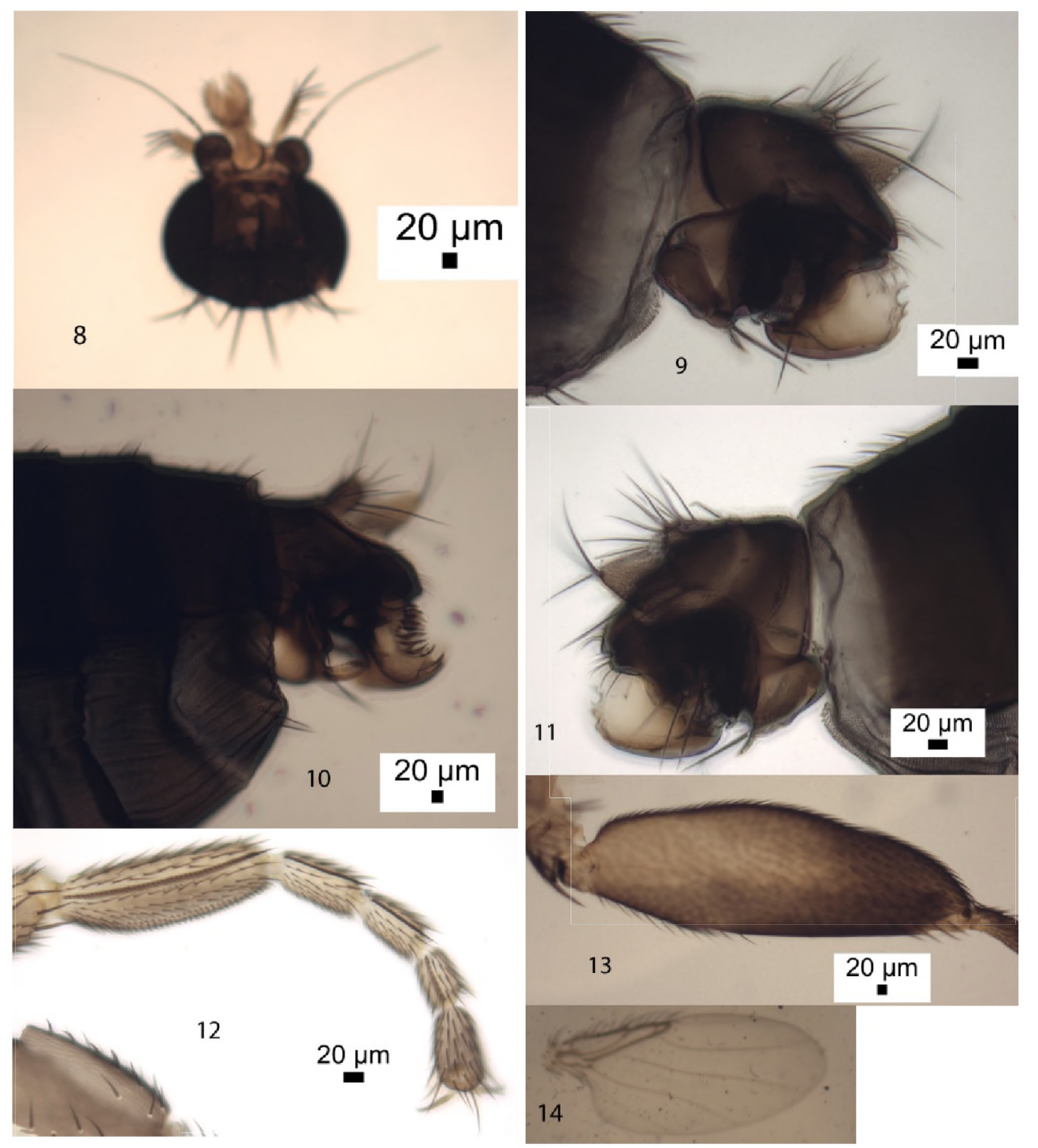

Figs 8-14. Megaselia museoconfluentis n. sp., male: 8 - frontal view of head; 9-10 - left faces of hypopygia of two different specimens; 11 - right face of hypopygium; 12 - front tarsus; 13 - hind femur; 14 - wing. 
Legs mainly brown but not dark brown, with the front leg being palest (especially the distal halves of the coxa being more yellowish). Fore tarsus (Fig. 12) with posterodorsal hair palisade on segments 1-4 and 5 longer than 4 . The front basitarsus thicker than segment 2 and with 2-3 rows of the posteroventral hairs reduced to small spinules. Dorsal hair palisade of mid tibia extends almost two thirds of its length. Hairs below basal half of hind femur shorter than those of anteroventral row of outer half (Fig. 13). Hind tibia with about 20 differentiated posterodorsal hairs and spinules of apical combs simple. Wing (Fig. 14) 1.7-2.3 mm long. Costal index $0.43-0.47$. Costal ratios 2.6-4.9:1.2-2.0:1. Costal cilia (of section 3) $0.15-0.21$ $\mathrm{mm}$ long. A small hair at base of vein 3 . With $4-6$ axillary bristles, the outermost being $0.13-$ $0.19 \mathrm{~mm}$ long, but always slightly shorter than costal cilia. Sc not reaching R1. Thick veins light brown, thin veins $4-6$ brown but 7 pale grey. Membrane only very lightly tinged grey (not evident to naked eye when viewed against a white background). Haltere brown. Abdominal tergites brown with hairs, the longest being posterolaterally on $\mathrm{T} 2$ to $\mathrm{T} 5$ and even longer on $\mathrm{T} 6$. Venter brownish grey and with hairs on segments 5 and 6 but those on 3 and 4 being minute and much finer (and easily overlooked at low magnifications). Hypopygium mainly brown, with a paler brownish grey anal tube, and paler hypandrial lobes (Figs 9-11). The greatly enlarged right paraphysis of the penis complex, with its comb like rear margin is highly distinctive

Material examined. Holotype male, France, Sallanches, Le Crêt de Saint-Martin, Aug 2012, R. Siffointe (M45, University of Cambridge, Museum of Zoology, 8-173). 10 paratype males as holotype except 5 were vi \& x. 2013 (UCMZ and Museum of the Confluences, Lyon, 8-174).

Etymology. Named after the Museum of the Confluences in Lyon; situated at the confluence of two rivers, the Saone and the Rhone. RS's collection of Phoridae is to be deposited in this museum.

\section{Megaselia siffointei Disney n. sp.}

(Figs 15-20)

Diagnosis (male). In the key to the males of the British species (Disney 1989) this species runs to couplet 285 , lead 1 , to $M$. eisdelderae Schmitz, from which it differs by its entirely dark brown thoracic scutum and abdominal tergites; apart from the hypopygium.

Male. Frons brown, clearly broader than long, with 40-48 hairs and dense but very fine microtrichia. Supra-antennal bristles (SAs) unequal, the lower pair being about half as long as the upper SAs. The antials a little lower on frons than anterolaterals (ALs), and about three quarters as far from upper SAs as either is from an AL bristle. Pre-ocellars about as far apart as either is from a mediolateral bristle, which is at about the same level on frons. Cheek with 4 bristles and jowl with a single longer one. The subglobose postpedicel (Fig. 16) brown, without subcutaneous pit sensilla (SPS) vesicles. Palp (Fig. 15) yellow, about a third as broad as postpedicel but a little longer than breadth of latter, with $7-10$ bristles (the longest being about 0.6 times as long as palp) and 1-4 hairs. Labrum (Fig. 15) pale yellow and about 1.3-1.4 times as wide as a postpedicel. Labella coloured as labrum and with very few short spinules below. Thorax brown. Three notopleural bristles and no cleft in front of these. Mesopleuron bare. Scutellum with an anterior pair of hairs (subequal to those in middle of scutum) and a posterior pair of bristles. Apart from brown patch on mid coxa, legs essentially yellow, but hind femur gradually lightly tinged brown towards tip. Fore tarsus with posterodorsal hair palisade on segments 1-5. Dorsal hair palisade of mid tibia extends almost two thirds its length. Hairs below basal half of hind femur clearly longer than those of anteroventral row of outer half (Fig. 19). Hind tibia with 16-18 differentiated posterodorsal 
hairs and spinules of apical combs simple. Wing (Fig. 20) $1.5-1.7 \mathrm{~mm}$ long. Costal index $0.45-0.52$. Costal ratios 3.2-4.0:2.1-2.6:1. Costal cilia (of section 3) $0.07-0.09 \mathrm{~mm}$ long. No hair at base of vein 3 . With 2 axillary bristles, the outer being $0.10-0.13 \mathrm{~mm}$ long and thus longer than costal cilia. Sc not reaching R1. Costa only lightly tinged brown, the rest of veins brown but not dark and vein 7 paler than veins $4-6$. Membrane only very lightly tinged grey (not evident to naked eye when viewed against a white background). Haltere knob yellow. Abdominal tergites brown with hairs longest at rear of T6. Venter grey, and with hairs on segments 3-6. Hypopygium mainly brown, with paler hypandrial lobes and with a pale greyish anal tube, and as Figs 17 and 18 .

Material examined. Holotype male, France, Sallanches, Le Crêt de Saint-Martin, Sep 2012, R. Siffointe (MX, University of Cambridge, Museum of Zoology, 8-173). 4 paratype males as holotype, except some Oct 2012.7 paratype males as holotype except 16 Oct 2013 (UCMZ and Museum of the Confluences, Lyon, 8-174).

Etymology. Named after René Siffointe.
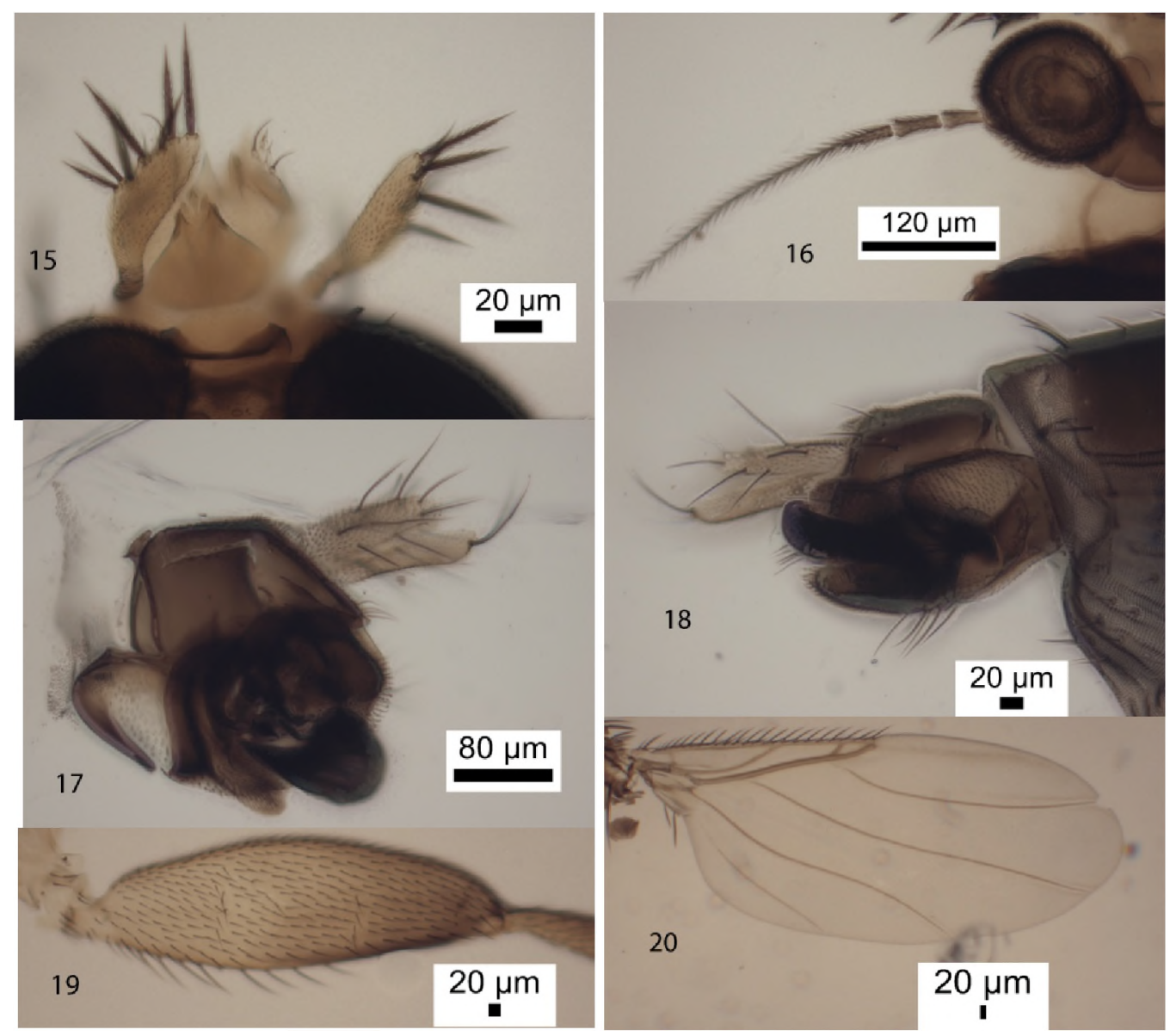

Figs 15-20. Megaselia siffointei $n$. sp., male: 15 - palps and labrum; 16 - left antenna; 17 - left face of hypopygium; 18 - right part ventral face of hypopygium; 19 - hind femur; 20 - wing. 


\section{Megaselia similipropinqua n. sp.}

(Figs 21-27)

Diagnosis (male). In the key to the males of the British species (Disney 1989) this species runs to couplet 279 , to $M$. propinqua (Wood), which it closely resembles. It differs from $M$. propinqua in having the base of the hind femora yellow, the left lobe of the hypandrium in the new species is paler, and its microtrichia end before the tip, and the right lobe is larger.

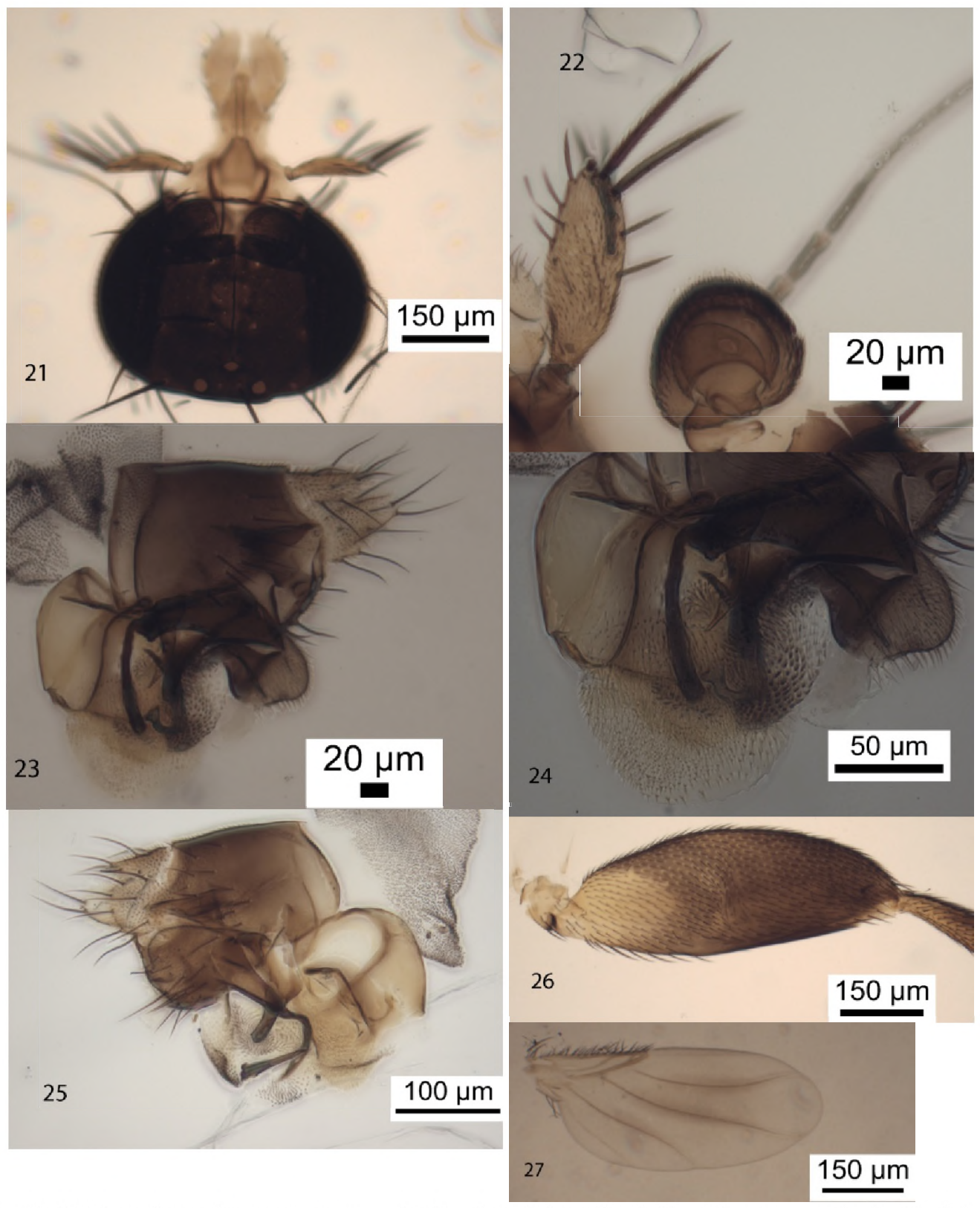

Figs 21-27. Megaselia similipropinqua n. sp., male: 21 - frontal view of head; 22 - right antenna and palp; 23 - left face of hypopygium, 24 - left lobe of hypandrium; 25 - right face of hypopygium; 26 - hind femur; 27 - wing. 
Male. Head (Fig. 21) with frons brown, clearly broader than long, with 40-50 hairs and dense but very fine microtrichia. Supra-antennal bristles (SAs) unequal, the lower pair being about two thirds as long as upper SAs. Antials lower on frons than anterolaterals, and about midway between an upper SA and an AL bristle. Pre-ocellars about as far apart as either is from a mediolateral bristle, which is slightly higher on frons. Cheek with 3-4 bristles and jowl with two that are longer. The subglobose postpedicel brown (Fig. 22), with at most 2 subcutaneous pit sensilla (SPS) vesicles. Palp (Fig. $21 \& 22$ ) dusky yellow, 0.3-0.4 times as broad as its length but 1.3-1.4 times as long as breadth of postpedicel, with 8-10 bristles and 3-8 hairs; with longest bristles about 0.9 times the length of the palp. Labrum (Fig. 21) pale yellow and about three quarters the width of postpedicel. Labella coloured as labrum and with very few short spinules below. Thorax brown. Three notopleural bristles and no cleft in front of these. Mesopleuron bare. Scutellum with an anterior pair of hairs (subequal to those in middle of scutum) and a posterior pair of bristles. Apart from brown patch on mid coxa, front and middle legs yellow; but hind leg brown apart from the base of the hind femur is yellow (Fig. 26). Fore tarsus with posterodorsal hair palisade on segments $1-4$ and 5 slightly longer than 4 . Dorsal hair palisade of mid tibia extends about 0.7 times its length. Hairs below basal half of hind femur longer than those of anteroventral row of outer half (Fig. 26). Hind tibia with about 20 differentiated posterodorsal hairs, but those of basal third are only weakly differentiated, and spinules of apical combs simple. Wing (Fig. 27) 1.3-1.4 mm long. Costal index 0.35-0.39. Costal ratios 3.9-4.2:1.5-1.7: 1. Costal cilia (of section 3) $0.06-0.07 \mathrm{~mm}$ long. With a small hair at base of vein 3. With 2 axillary bristles, the outer being $0.08-0.09 \mathrm{~mm}$ is a little longer than costal cilia. Sc not reaching R1. Thick veins pale brown, thin veins $4-6$ brown and 7 pale grey. Membrane only lightly tinged grey (not evident to naked eye when viewed against a white background). Haltere brown. Abdominal tergites brown with longest hairs at rear of T6. Venter grey and with hairs on segments 3-6. Hypopygium (Figs 23-25) with mainly brown epandrium, mainly yellow hypandrium, whose left lobe is pale with its microtrichia ending before the tip, and with a pale grey anal tube.

Material examined. Holotype male, France, Sallanches, Le Crêt de Saint-Martin, Jul 2005 , R. Siffointe (M9, University of Cambridge, Museum of Zoology, 8-173). Paratypes 1 male as holotype; 6 males as holotype except Oct 2013 (UCMZ and Museum of the Confluences, Lyon, 8-174).

Etymology. The name refers to its close resemblance to $M$. propinqua.

\section{ACKNOWLEDGEMENTS}

RHLD's studies of Phoridae are currently supported by grants from the Balfour-Browne Trust Fund (University of Cambridge).

\section{REFERENCES}

DISNEY R. H. L. 1987. Rescue of Megaselia fenestralis (Diptera: Phoridae) from synonymy and its removal from British List. Entomologist's Gazette 38: 13.

Disney R. H. L. 1988. Three new species of Megaselia (Dipt., Phoridae) from the British Isles, plus new synonyms. Entomologist's Monthly Magazine 124: 7-14.

DISNEY R. H. L. 1989. Scuttle Flies - Diptera Phoridae Genus Megaselia, Handbooks for the Identification of British Insects, $10(8): 1-155$.

DISNEY R. H. L. 2001. The preservation of small Diptera. Entomologist's Monthly Magazine 137: 155-159.

DiSNEY R. H. L. \& DURSKA E. 1998. A new genus and new species of Phoridae (Diptera) from Poland. European Journal of Entomology 95: 437-453.

SCHMtz H. 1957. Phoridae. In: LINDNER E (ed.), Die Fliegen der palaearktischen Region 4(33) (Lieferung 196): $417-464$.

SCHMLTZ H. 1958. Phoridae. In: LINDNER E (ed.), Die Fliegen der palaearktischen Region 4(33) (Lieferung 202): $465-512$. 
SCHMাZ H. \& BEYER, E. 1965. Phoridae. In: LINDNER E (ed.), Die Fliegen der palaearktischen Region 4(33) (Lieferung 258, 260): 513-608.

Schmtz H.\& Delage, A. 1974. Phoridae. In: LIndner E (ed.), Die Fliegen der palaearktischen Region 4(33) (Lieferung 301): 638-664.

\section{STRESZCZENIE}

\section{[Cztery nowe gatunki z rodzaju Megaselia Rondani (Diptera: Phoridae) z Francji]}

W materiale Phoridae zebranym w pobliżu domu Rene Siffointe (Sallanches, Francja region Rodan-Alpy) zostaly stwierdzone (RHLD) cztery nowe dla nauki gatunki z rodzaju Megaselia: M. betrugspinata Disney sp. n., M. museoconfluentis Disney sp. n., $M$ siffointei Disney sp. n. and $M$. similipropinqua Disney sp. n. Wśród gatunków zadrowatych, znaleziony zostal także gatunek Megaselia marekdurskii Disney, wcześniej wykazany tylko z Polski. 